\title{
Protein identification from the parotoid macrogland secretion of Duttaphrynus melanostictus
}

\author{
Douglas Oscar Ceolin Mariano', Marcela Di Giacomo Messias², Patrick Jack Spencer², \\ Daniel Carvalho Pimenta ${ }^{1, *}$ \\ ${ }^{1}$ Laboratory of Biochemistry and Biophysics, Butantan Institute, São Paulo, SP, Brazil. \\ ${ }^{2}$ Biotechnology Center, Nuclear and Energy Research Institute (IPEN), São Paulo, SP, Brazil.
}

\section{Keywords:}

Amphibian skin secretion

Bufonidae

Duttaphrynus melanostictus

Proteomics

Batch chromatography

Asian common toad

\begin{abstract}
Background: Bufonid parotoid macrogland secretion contains several low molecular mass molecules, such as alkaloids and steroids. Nevertheless, its protein content is poorly understood. Herein, we applied a sample preparation methodology that allows the analysis of viscous matrices in order to examine its proteins.

Methods: Duttaphrynus melanostictus parotoid macrogland secretion was submitted to ion-exchange batch sample preparation, yielding two fractions: salt-displaced fraction and acid-displaced fraction. Each sample was then fractionated by anionic-exchange chromatography, followed by in-solution proteomic analysis.

Results: Forty-two proteins could be identified, such as acyl-CoA-binding protein, alcohol dehydrogenase, calmodulin, galectin and histone. Moreover, de novo analyses yielded 153 peptides, whereas BLAST analyses corroborated some of the proteomicidentified proteins. Furthermore, the de novo peptide analyses indicate the presence of proteins related to apoptosis, cellular structure, catalysis and transport processes. Conclusions: Proper sample preparation allowed the proteomic and de novo identification of different proteins in the D. melanostictus parotoid macrogland secretion. These results may increase the knowledge about the universe of molecules that compose amphibian skin secretion, as well as to understand their biological/physiological role in the granular gland.
\end{abstract}

* Correspondence: dcpimenta@butantan.gov.br http://dx.doi.org/10.1590/1678-9199-JVATITD-2019-0029 Received: 06 May 2019; Accepted: 11 July 2019; Published online: 19 August 2019 


\section{Background}

Anuran skin participates in different physiological process and has an important role in chemical defense [1-4]. In these animals, the tegument contains specialized glands, termed granular glands, capable of storing a higher diversity of biological molecules [1, 4-6]. However, some anurans developed glandular accumulation on different body regions. One example is the Bufonidae family, which possess a parotoid macrogland located in the dorsum of the head $[7,8]$.

Bufonid parotoid macrogland secretion contains a wide quantity of alkaloids and steroids. Several studies purified and biologically and/or chemically characterized these molecules on Bufo or Rhinella species [9-12]. In relation to peptides, Rash et al. [13] identified these molecules in low abundance in $R$. marina. Recently, Huo et al. [14] identified 939 unique peptides in $B$. gargarizans parotoid macrogland secretion by de novo approach.

Proteins are also present in bufonids. Sciani et al. [15] investigated the protein profile of parotoid macrogland secretion of nine bufonids (Rhinella sp. and Rhaebo sp.). The authors showed the presence of several proteins by electrophoresis. Other two researches identified and characterized baserpin and lysozyme from $B$. andrewsi parotoid macrogland secretion [16, 17]. Besides that, proteomics studies performed with $B$. bufo, $B$. gargarizans and $R$. schneideri parotoid macrogland secretion identified 13, 8 and 104 proteins, respectively [14, 18, 19].

In bufonids, protein identification and/or characterization from parotoid macrogland secretion may be limited, mainly because this biological sample is highly viscous, sticky and often water insoluble $[15,20]$. Recently, our group developed a methodology to analyze viscous secretions [21]. Employing the ion-exchange batch sample preparation methodology, we were able to biochemically characterize the parotoid macrogland secretion of the Asian common toad Duttaphrynus melanostictus, including the retrieval of peptidasic activity, as assessed by zymography [21].

Since our sample preparation step yielded to a proteinrich solution, we performed an in-solution proteomics and de novo peptide sequencing after anion-exchange batch sample processing of $D$. melanostictus parotoid macrogland secretion.

\section{Material and Methods}

\section{Reagents}

All employed reagents were purchased from Sigma Co. (St. Louis, MO, USA), unless otherwise stated. Amicon Ultra-4 Centrifugal $3 \mathrm{kDa}$ filter and syringe filter (Millex-GV, hydrophobic PVDF $0.22 \mu \mathrm{m}$ ) were purchased from Millipore, USA. pH test strip (pHFix 0-14) was obtained from Macherey-Nagel, Germany. QAESephadex A-25 was obtained from Pharmacia Fine Chemicals AB Uppsala, Sweden.

\section{Skin secretion collection}

D. melanostictus lyophilized parotoid macrogland secretion was kindly provided by Venom Supplies Pty ltd., Australia.

\section{Anionic-exchange batch sample methodology}

\section{Sample preparation}

The material was analyzed according to the protocol developed by Mariano et al. [21] as follows:

Step 1 - resin preparation: we resuspended $0.5 \mathrm{~g}$ of QAE Sephadex A-25 resin with $12.5 \mathrm{~mL}$ of $25 \mathrm{mM}$ ammonium bicarbonate $(\mathrm{pH} 8.5)$ for $18 \mathrm{~h}$, at room temperature. Then, the tube was centrifuged at $500 \mathrm{~g}$, for $5 \mathrm{~min}$, and the supernatant was discarded. After that, the resin was washed with $12.5 \mathrm{~mL}$ $25 \mathrm{mM}$ of ammonium bicarbonate during 30 minutes; after, the tube was centrifuged (500 g, $5 \mathrm{~min}$ ) and the supernatant was discarded. We repeated this last process twice.

Step 2 - sample preparation: D. melanostictus lyophilized parotoid macrogland secretion $(\sim 100 \mathrm{mg})$ was resuspended in $20 \mathrm{~mL}$ of $25 \mathrm{mM}$ ammonium bicarbonate $(\mathrm{pH} \mathrm{8.5)}$ under constant agitation, followed by sonication. We transferred the solution to a tube containing the anionic resin.

Step 3 - unbound fraction: we maintained the tube under constant homogenization during $1 \mathrm{~h}$, at room temperature. After that, we centrifuged the tube ( $500 \mathrm{~g}$, during $5 \mathrm{~min}$ ), collected the supernatant and termed it as 'anionic unbound fraction' (A-UBF). Then, we added $20 \mathrm{~mL}$ of $25 \mathrm{mM}$ ammonium bicarbonate $(\mathrm{pH}$ 8.5) at the tube and left $1 \mathrm{~h}$ under constant homogenization. The sample was centrifuged and the supernatant was collected and pooled as A-UBF.

Step 4 - salt fraction: following the removal of A-UBF fraction, we added $25 \mathrm{mM}$ ammonium bicarbonate, containing $2 \mathrm{M} \mathrm{NaCl}$ ( $\mathrm{pH}$ 8.5). Here, we conducted this phase as described in step 3: homogenization $(1 \mathrm{~h}$ ) and centrifugation (500 g, during $5 \mathrm{~min}$ ); however, we collected the supernatant and termed it as 'anionic salt-displaced fraction' (A-SDF). This step was repeated twice.

Step 5 - acid fraction: finally, we added $25 \mathrm{mM}$ ammonium bicarbonate $(\mathrm{pH} \sim 3-4)$. Again, we repeated this step twice: homogenization ( $1 \mathrm{~h}$ ), centrifugation (500 g, during $5 \mathrm{~min}$ ) and supernatant collection [termed as 'anionic acid-displaced fraction' (A-ADF)].

A-SDF and A-ADF were mechanically filtered $(.22 \mu \mathrm{m}$ syringe filters) prior to lyophilization.

\section{Desalting}

A-SDF and A-ADF were desalted by a HiPrep 26/10 desalting column (GE Healthcare) coupled to an AKTA avant 25 preparative system (GE Healthcare). We resuspended all samples in $5 \mathrm{~mL}$ of $25 \mathrm{mM}$ Tris ( $\mathrm{pH}$ 8.5) and individually loaded into the system. The column eluted at a constant flow rate of $10 \mathrm{~mL} /$ min with $25 \mathrm{mM}$ Tris buffer ( $\mathrm{pH} 8.5$ ) and monitored at $220 \mathrm{~nm}$. We collected each peak corresponding to a protein signal and subsequently all samples were lyophilized.

\section{Chromatographic analysis}

Both desalted fractions were concentrated using an Amicon Ultra- 4 centrifugal filter $(3 \mathrm{kDa})$, dried, resuspended in $2 \mathrm{~mL}$ of $25 \mathrm{mM}$ Tris ( $\mathrm{pH}$ 8.5) and individually loaded into a Mono 
Q 5/50 GL column, in a two-buffer system: (1) $25 \mathrm{mM}$ Tris (pH 8.5) and (2) $25 \mathrm{mM}$ Tris, $2 \mathrm{M} \mathrm{NaCl}$ (pH 8.5). The column was eluted at a constant flow rate of $1 \mathrm{~mL} \cdot \mathrm{min}^{-1}$ under a 0 to $50 \%$ gradient of buffer 2, during $20 \mathrm{~min}$. We monitored the eluates at $220 \mathrm{~nm}$ and automatically collected one $\mathrm{mL}$ fractions during the gradient phase.

\section{Proteomic analysis: in-solution digestion}

We dried aliquots of the A-SDF (1-10) and A-ADF (1- 6) fractions and resuspended each fraction in $8 \mathrm{M}$ urea $(100 \mathrm{mM}$ TrisHCL, pH 8.5) and Tris(2-carboxyethyl)phosphine hydrochloride (TCEP), $5 \mathrm{mM}$ final concentration, for $1 \mathrm{~h}$, at room temperature. After that, we added iodoacetamide (IAA) (dissolved in water) (10 $\mathrm{mM}$ final concentration) and incubated all samples for $1 \mathrm{~h}$, at room temperature and protected from the light. Next, we added $100 \mathrm{mM}$ Tris- $\mathrm{HCl}(\mathrm{pH} 8.5)$, for urea dilution (2 M final concentration), and $10 \mu \mathrm{L}$ trypsin $\left(10 \mathrm{ng} \cdot \mu \mathrm{L}^{-1}\right.$ in $100 \mathrm{mM}$ Tris- $\mathrm{HCl}, \mathrm{pH} 8.5$ ) and incubated all samples during $18 \mathrm{~h}$, at $30^{\circ} \mathrm{C}$. Finally, we stopped the enzymatic reaction adding $50 \%$ $\mathrm{ACN} / 5 \% \mathrm{TFA}$ and dried all samples. Prior to analysis in the mass spectrometer, we used a ZipTip ${ }^{\varpi} \mathrm{C}-18$ pipette tips (Millipore) to desalt and for peptide concentration.

We analyzed all samples in an electrospray ionization quadrupole time-of-flight (ESI-Q-TOF) (Micromass, UK) equipped with binary ultra-performance liquid chromatography system (UPLC) (Acquity, Waters, MA, USA). Samples $(5 \mu \mathrm{L})$ were separated on a C18 column, using the following mobile phase: (A) $0.1 \%$ formic acid (FA) $(1: 999, \mathrm{v} / \mathrm{v})$ and (B) $0.1 \%$ FA in $90 \%$ acetonitrile $(\mathrm{ACN})(1: 900: 99, \mathrm{v} / \mathrm{v} / \mathrm{v})$. The gradient condition was: $2 \% \mathrm{~B}$ in $0-5 \mathrm{~min} ; 2-40 \% \mathrm{~B}$ in $5-60 \mathrm{~min}$. The mass spectrometry (MS) was equipped with a locked ESI probe and operated in positive mode (ESI+). The electrospray capillary voltage was $3.1 \mathrm{kV}$, with a cone voltage of $113 \mathrm{~V}$. The cone and desolvation gas flows were 185 and $600 \mathrm{l} \mathrm{h}-1$, respectively. The desolvation temperature was $150^{\circ} \mathrm{C}$. MS scans were acquired at 350-1600 mass charge rate $(\mathrm{m} / \mathrm{z})$ and $\mathrm{MS} / \mathrm{MS}$ scans at $50-2000 \mathrm{~m} / \mathrm{z}$. The collision energy of the MS/MS analysis was $10-10.6 \mathrm{eV}$. The software selected automatically ions with a threshold intensity of $\geq 10$ for fragmentation.

\section{Data processing}

We loaded and analyzed micromass RAW files by Peaks Studio V7.0 software (BSI, Canada). We adjusted the following parameters for de novo peptide sequencing: error tolerance (MS and MS/MS) was set to 0.2 Da; methionine oxidation and carbamidomethylation as variable and fixed modification, respectively; trypsin as cleavage enzyme; and average local confidence (ALC) $\geq 80 \%$. We performed a basic local alignment search tool (BLAST) with all de novo peptides, limiting the search for Amphibia class (taxid: 8292). For a deeper analysis, we only consider alignments presenting the higher scores.

For proteomic identification, we set the following parameters on Peaks software: error tolerance (MS and MS/MS) set to 0.2
Da; methionine oxidation and carbamidomethylation as variable and fixed modification, respectively; trypsin as cleavage enzyme; three maximum missed cleavages; three maximum variable PTMs per peptide; one non-specific cleavage; false discovery rate was $\leq 1 \%$; and we analyzed all data against Amphibia protein database (167530 entries) (built by retrieving all Uniprot entries associated with this taxon).

\section{Results}

\section{Chromatographic analysis of $D$. melanostictus parotoid macrogland secretion after batch sample preparation}

After batch processing, we analyzed A-SDF and A-ADF by anionic-exchange chromatography. According to the chromatographic profile and peak distribution, we obtained a total of 10 and 6 fractions from A-SDF and A-ADF, respectively. The resulting profiles are very similar to those previously obtained. Please refer to Figure 3 in Mariano et al. [21].

\section{Mass spectrometry analysis Proteomic Identification}

We identified 24 proteins in A-SDF collected fractions (Table 1), being 18 proteins identified in fractions 3-7, after in solution digestion. Proteins such as acyl-CoA-binding protein homolog, alcohol dehydrogenase, calmodulin 1, diazepam binding inhibitor, galectin-1, histone $\mathrm{H} 2 \mathrm{~B}$ and prostaglandin reductase 1 were found in more than one fraction. Only in A-SDF fraction 1 no protein was identified.

Furthermore, we identified 18 proteins in A-ADF collected fractions (Table 2), being six of them already identified in A-SDF. In the acid fraction, we can highlight the presence of the protein ATP synthase (subunit alpha and beta) and also hemoglobin (subunit beta).

Based on the Gene Ontology (GO) project [22], employing the 'molecular function' identifier, we observed that proteins present in A-SDF were associated to binding (four proteins) and/ or catalytic activities (seven proteins). While in A-ADF, besides binding activity (12 proteins), we also found proteins classified into nucleoside-triphosphatase activity (five proteins), oxygen carrier activity (one protein), structural molecule activity (three proteins) and transmembrane transporter activity (two proteins).

\section{de novo peptides}

This analysis led us to the identification of 102 and 41 different de novo peptides in A-SDF and A-ADF collected fractions, respectively (Additional files 1 and 2). Among them, only ten de novo peptides were present in both fractions.

BLAST alignment showed that several de novo peptides aligned with proteins already identified in our proteomic study, like acyl-CoA-binding protein, alcohol dehydrogenase, galectin and prostaglandin reductase 1 (Additional files 1 and 2, Blast E-value $<0.01$, color code: light red). The remaining de novo peptides suggest proteins related to: apoptosis (apoptosis regulator Bcl-2- 


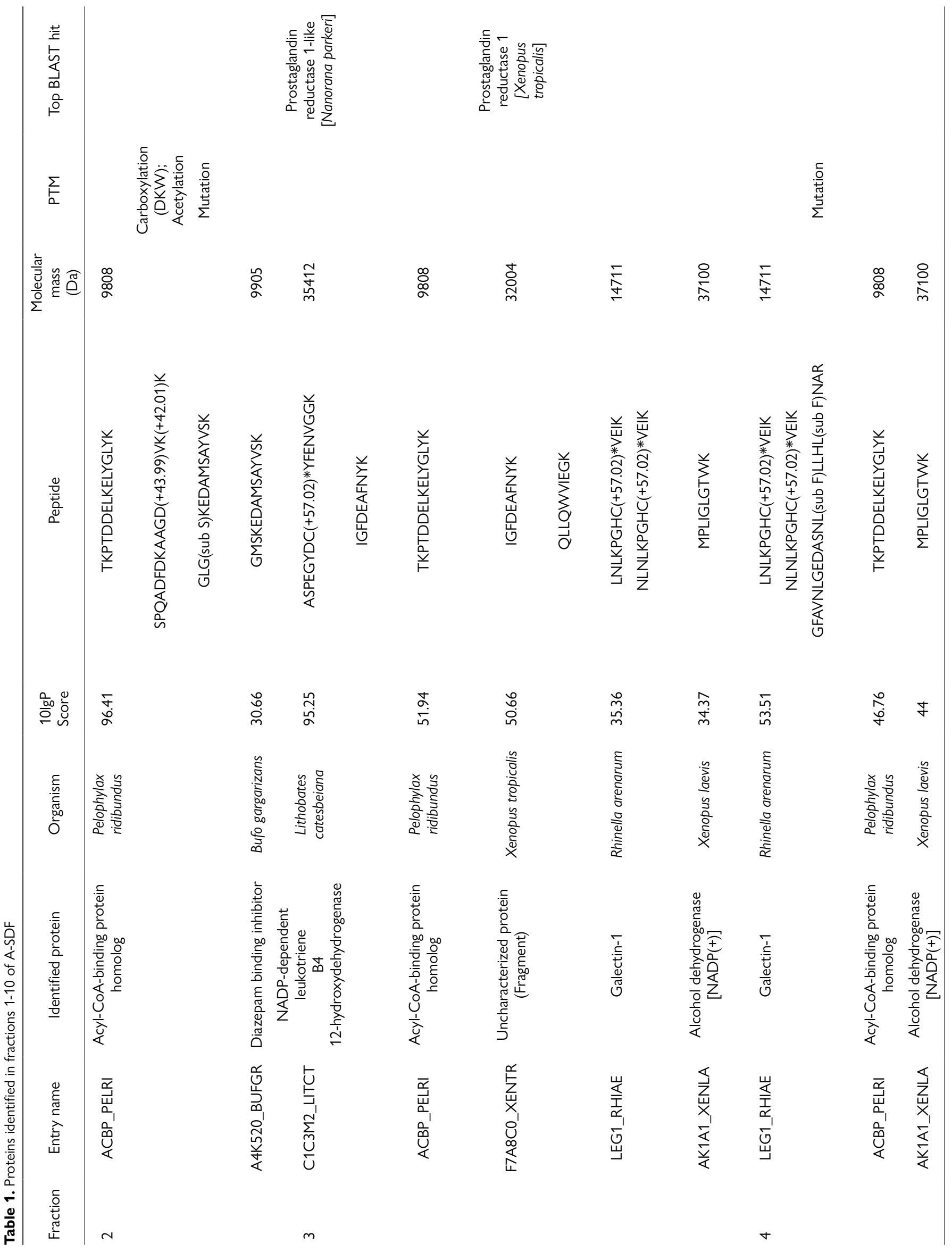




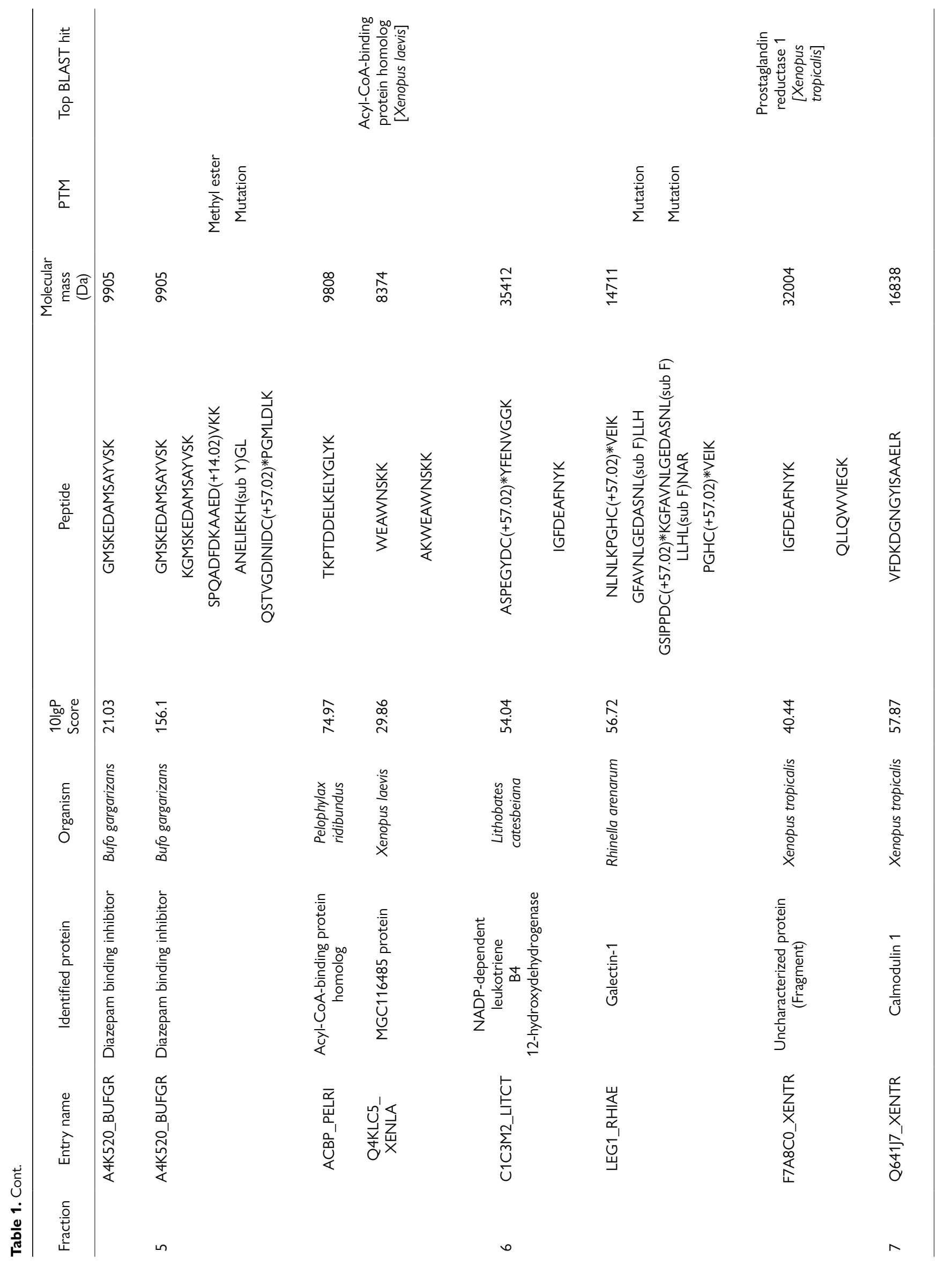




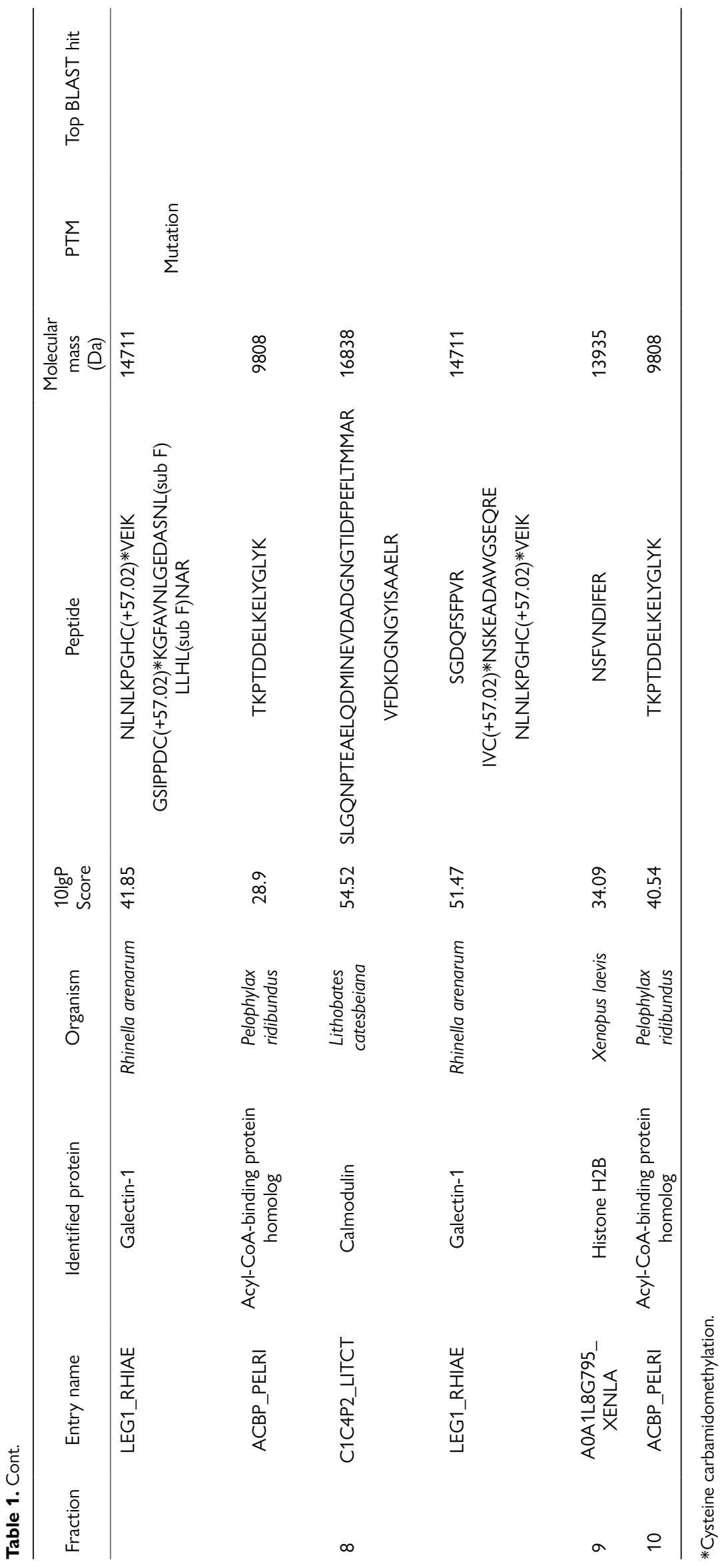




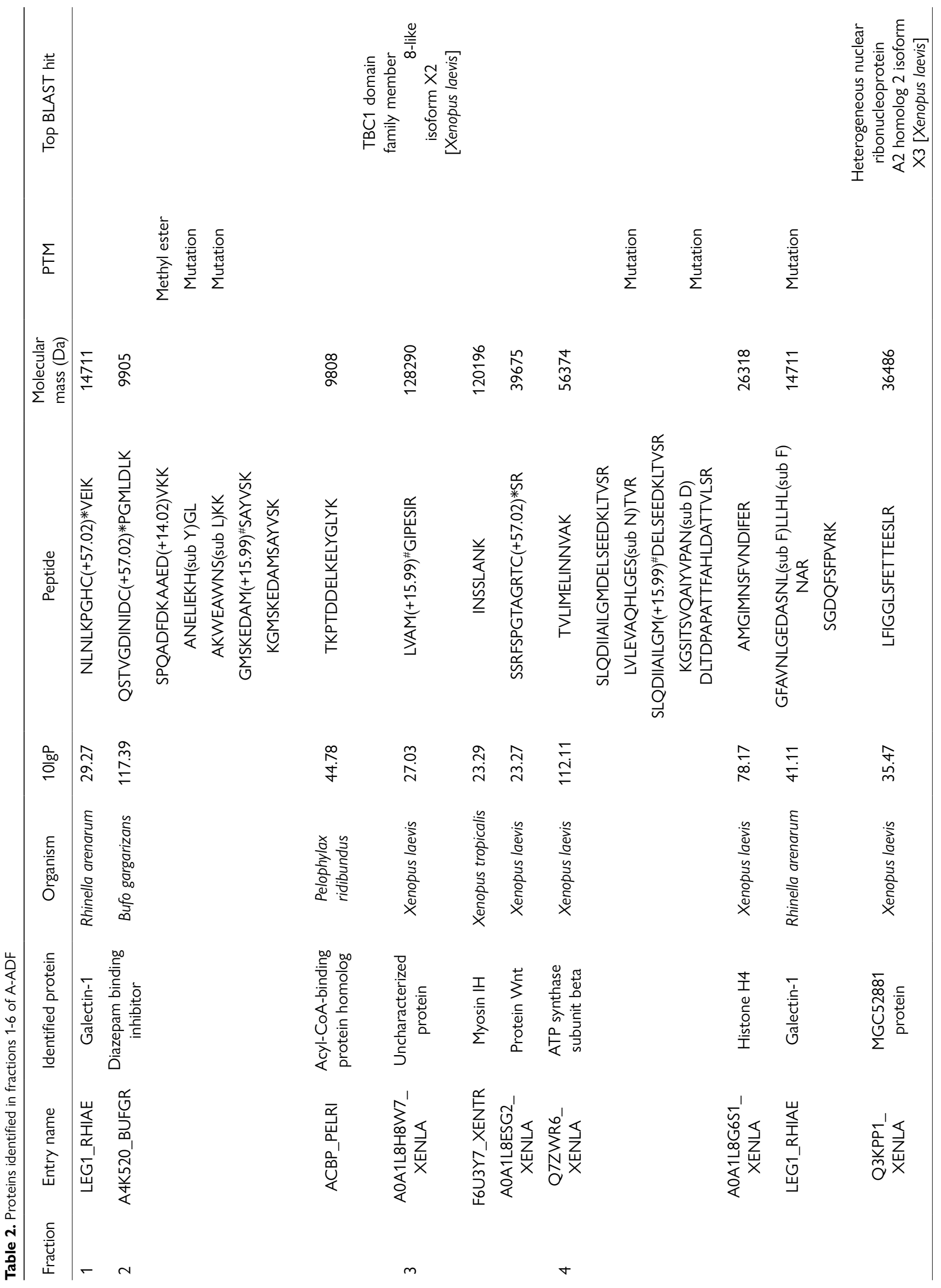




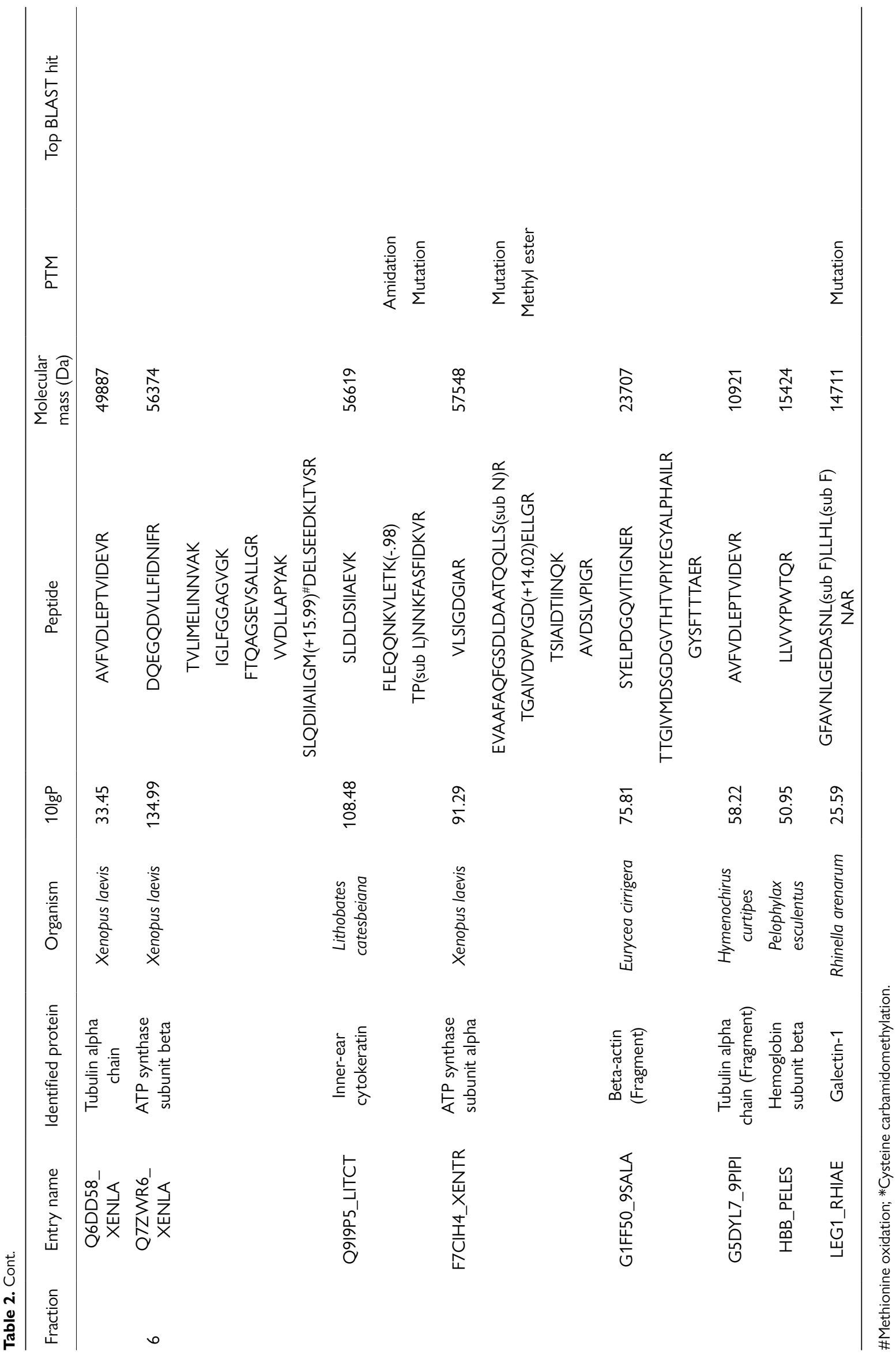


like), binding activity (spectrin beta chain, non-erythrocytic 4; FYN-binding protein-like; FRAS1-related extracellular matrix protein 3), cytoskeleton (keratin; neurofilament light polypeptide), fertilization (zona pellucida sperm-binding protein 4-like), enzymatic activity (hexokinase-2-like; protein ABHD14B-like; serine/threonine-protein kinase akt-1-like; UDP-GlcNAc:betaGal beta-1,3-N-acetylglucosaminyltransferase 9) and transport (golgi to ER traffic protein; large neutral amino acids transporter; apolipoprotein B-100) (Blast E-value < 1, color code: light blue).

It is also important to mention that de novo BLAST alignment suggest the presence of the following proteins (Additional files 1 and 2) (Blast E-value > 1, color code: light green): antimicrobial peptide precursor, catechol O-methyltransferase-like, cytochrome P450, estradiol 17-beta-dehydrogenase 12-B-like $S$, integumentary mucin B.1, metalloproteinase ADAM10-like protein, $\mathrm{NADH}$ dehydrogenase subunit $6, \mathrm{~N}$-acetylneuraminate lyase, pappalysin-1, phospholipid-transporting ATPase IC-like, phospholipase $\mathrm{A} 2$ crotoxin basic subunit $\mathrm{CBb}$-like, proteasome $26 \mathrm{~S}$ subunit, protein kinase $\mathrm{C}$ delta type-like, protein-tyrosine kinase 2-beta, proteoglycan 4, squalene synthase-like, trans-1,2dihydrobenzene-1,2-diol dehydrogenase-like and trefoil factor 2-like. We also found uncharacterized proteins in our analysis (Additional files 1 and 2).

\section{Discussion}

Bufonidae is a worldwide amphibian taxon popularly known as the true toads. These anurans store a huge arsenal of bioactive molecules in their parotoid macroglands, such as alkaloids and steroids $[5,10,12,23]$.

However, only a few studies focus on the biochemical and/or biological characterization/identification of proteins in bufonids. One explanation is that the parotoid macrogland secretion exhibit a viscous aspect, which difficult its solubilization. Another point to highlight is the higher quantity of low molecular mass molecules, which makes necessary to prepare properly the sample prior to the protein study.

Huo et al. [14] submitted B. gargarizans parotoid macrogland secretion to a cut-off filter $(10 \mathrm{kDa})$. Based on de novo sequencing, the authors obtained $\mathrm{a}<10 \mathrm{kDa}$ fraction rich in peptides. This fraction exhibited anti-proliferative activity on SMMC-7721 cells under different concentrations. However, the authors do not comment about the presence of low molecular mass molecules in $<10 \mathrm{kDa}$ fraction; neither if these molecules were removed nor how they did it.

In another study, Rash et al. [13] submitted R. marina parotoid macrogland secretion to two sample preparation steps: dialysis (to remove molecules below $1 \mathrm{kDa}$ ) and subsequently, cut-off membrane filter (to remove molecules over $10 \mathrm{kDa}$ and insoluble material). When the authors analyzed the $<10 \mathrm{kDa}$ fraction (termed peptide-enriched sample), they found that the peptide abundance in this material was very low (the authors sequenced only 14 de novo peptides). Furthermore, even after dialysis and membrane filter, this material contained high quantities of low molecular mass molecules $(<900 \mathrm{Da})$.
Utilizing a different approach, Mariano et al. [21] observed a similar result as obtained by Rash et al. [13]. After analyzing $D$. melanostictus parotoid macrogland secretion by batch sample preparation, the authors obtained soluble protein fractions. However, in these soluble fractions they also observed the presence of low molecular mass molecules, however, in low abundance.

The presence of non-protein compounds (alkaloids, biogenic amines, mucus and steroids) interfere in many protein quantification assays [24]. Employing different chromatography strategies (gel filtration, ion exchange and high-performance liquid chromatography), $\beta \gamma$-CAT (a complex of non-lens $\beta \gamma$ crystallin and trefoil factor) [25], lysozyme [17] and KPHTI (a trypsin inhibitor) [26] were purified from Bombina maxima, $B$. andrewsi and Kaloula pulchra hainana skin secretion, respectively. Using a similar chromatography steps, Anjolette et al. [24] obtained active protein fractions active on the complement system [24].

Demesa-Balderrama et al. [27] and Cavalcante et al. [28] conducted proteomics studies with Lithobates spectabilis and Dermatonotus muelleri skin secretion after electrophoresis and classical in-gel digestion. However, such approaches are purely analytical and rely on protein separation by electrophoresis, not allowing (typically) protein recovery and/or subsequent biological/biochemical assays. Moreover, the scarce available omics databases impair proper proteomic identification.

We employed the ion-exchange batch processing protocol [21] to obtain soluble protein fractions from D. melanostictus parotoid macrogland secretion. Following this methodology, we identified by proteomics proteins already described in other studies, such as alcohol dehydrogenase [NADP(+)], calmodulin, galectin, histone $\mathrm{H} 2 \mathrm{~B}$ and prostaglandin reductase 1 [18, 27-29].

Alcohol dehydrogenase [NADP $(+)]$ is an enzyme belonging to the protein superfamily aldo-keto-reductases (AKRs), responsible for the reduction of aldehydes and ketones to primary and secondary alcohols [30]. Calmodulin is a $\mathrm{Ca}^{+2}$-receptor protein involved in signaling pathways, such as growth, metabolic homeostasis, osmotic control, proliferation or reproductive process, through interaction with multiple target proteins [31]. Galectins are a phylogenetically conserved family of lectins involved in different cell signaling pathways, in the immune system, and also in the adult and embryonic tissue development and differentiation [32]. Histones are proteins responsible for the nucleosome structure in eukaryotic cells [33]. Another identified enzyme, prostaglandin reductase 1 , is responsible for the irreversible degradation of prostaglandin $\mathrm{E}$ and $\mathrm{F}$, leukotriene B4 and lipoxin A4, all endogenous lipid mediators involved in immune response and inflammation, for example [34].

In this work, we also identified proteins related to: energy metabolism (ATP synthase subunit alpha and beta), oxygen transport (hemoglobin subunit beta) or structural activity (betaactin, inner-ear cytokeratin, myosin and tubulin). Furthermore, proteomic analysis revealed the presence of acyl-CoA-binding protein homolog (ACBP) and diazepam binding inhibitor (DBI). Previously, Deng et al. (deposited sequence with no paper 
associated) found acyl-CoA-binding protein homolog mRNA in B. garzarians venom (GenBank: DQ437101.1; ABD75368.1); recently, Huo et al. [14] sequenced de novo peptides related to this protein in the aqueous extract of B. gargarizans parotoid macrogland secretion.

Studies showed that ACBP and DBI were the same protein $[35,36]$. ACBP is highly conserved among different organisms. The literature reports some biological activities of this protein: capacity to displace diazepam from the $\gamma$-aminobutyric acid (GABA) receptor in rat brain; to affect the cell growth; to bind to long-chain acyl-CoA esters; to stimulate steroidogenesis in isolated adrenal mitochondria; and to inhibit glucose inducing insulin secretion from pancreas [35, 37]. In addition, after inducing ACBP depletion in a mouse model, animals displayed reduced water content in the intercellular lipid membranes, which led to an elevated transepidermal water loss [38]. In this way, ACBP may act/help on physiological process that happens in anuran skin, once this organ is involved in gas-exchange, ionic and osmotic regulation, protection and thermoregulation [1-4]. The presence of steroid molecules in bufonid parotoid macrogland secretion $[9-12,15]$ may suggest the involvement of ACBP in the synthesis or transport of such molecules.

Moreover, we identified proteins involved in housekeeping function. Sousa-Filho et al. [18] found a similar protein profile in R. schneideri parotoid macrogland secretion (proteins related to carbohydrate metabolism, cell matrix, lipid metabolism, protein metabolism or uncharacterized proteins). Kowalski et al. [19] identified proteins involved in the antioxidant system (phospholipid hydroperoxide glutathione peroxidase), apoptosis (serine-threonine kinase), energy metabolism (muscle creatine kinase) or protein recycling (proteasome subunit a type-7-A) from $B$. bufo parotoid macrogland extract. The authors also identified a serine peptidase (snake venom serine protease homolog) that may exert toxic activity [19]. Rash et al. [13] suggested that the de novo peptides obtained from $R$. marina parotoid macrogland secretion were breakdown products of proteins involved in cell maintenance.

Each gland that composes the parotoid macrogland is a syncytial cell filled by cytoplasm. Several nuclei are present on the periphery of the gland, as well as organelles (Golgi stacks, mitochondria and rough endoplasmic reticulum). In a central position, we found several granules $[7,8]$. Upon mechanical pressure, the secretion expels/ejects much like a champagne cork. Therefore, cellular components can be expelled together with the secretion, like the cell machinery, cytoplasm, whole organelles and eventually nuclei [39]. Therefore, it was not unusual to identify house-keeping proteins in bufonid parotoid macrogland secretion.

De novo peptide sequencing relies on the determination of a peptide sequence directly from the mass spectrometry data, without the aid of a protein database [40]. Using this rationale, we deduced circa 150 de novo peptides from SDF and ADF fractions. After performing a BLAST search against Amphibia database, we proposed another dataset of proteins related to: binding, enzymatic activity or molecular transport (Additional files 1 and 2).
Furthermore, there were other interesting protein possibilities derived from that approach. However, due to the poor aligned E-value (but not a low ALC score) we will not discuss deeply these results, avoiding too much speculation. The only protein that we would call the attention is the antimicrobial peptide precursor (Additional file 1: fractions 3 and 4; Additional file 2: fraction 5). Recently, Shibao et al. [41] identified several classes of antimicrobial peptides in Rhinella schneideri skin glands by transcriptomic analysis. However, complementary studies are still necessary to confirm the actual existence of them.

Demesa-Balderrama et al. [27] performed an in-gel digestion and de novo peptide sequencing to study proteins from Lithobates spectabilis skin secretion. The authors found 111 de novo peptides, identifying 15 proteins (E-value $<0.077$ ). Nonetheless, their research discuss about the aspects that we must considerer when performing protein identification based on de novo peptides. One of them is the decreased number of amphibian skin proteins deposited in public data banks. Such problematic was also observed by Souza-Filho et al. [18] and in the present study, supporting the need for transcriptome studies with amphibian granular gland.

The IEX batch sample preparation led to the identification of 42 proteins in D. melanostictus parotoid macrogland secretion. These results may help to increase the knowledge on the amphibian skin secretion composition, as well as to infer possible biological activities exerted by these proteins. De novo peptide sequencing and subsequent BLAST alignment suggest a complementary protein dataset in D. melanostictus parotoid macrogland secretion.

\section{Acknowledgments}

The authors would like to thank Ismael Feitosa Lima, from the Center for Research on Toxins, Immune-Response and Cell Signaling (CeTICS) of Butantan Institute, for the technical assistance.

\section{Abbreviations}

SDF: salt-displaced fraction; ADF: acid-displaced fraction; A-UBF: anionic unbound fraction; A-SDF: anionic salt-displaced fraction; A-ADF: anionic acid-displaced fraction; TCEP: Tris(2carboxyethyl)phosphine hydrochloride; IAA: iodoacetamide; ESI-Q-TOF: electrospray-quadrupole-time of flight; UPLC: ultra-performance liquid chromatography system; FA: formic acid; CAN: acetonitrile; MS: mass spectrometry; ALC: average local confidence; AKR: aldo-keto-reductase; ACBP: acyl-CoAbinding protein homolog; DBI: diazepam binding inhibitor; GABA: $\gamma$-aminobutyric acid

\section{Availability of data and materials}

All data generated or analyzed during this study are included in this published article (and its supplementary information files).

\section{Funding}

This work was supported by the Coordination for the Improvement of Higher Education Personnel (CAPES - grant $n$. 
969130 to DOCM), the São Paulo Research Foundation (FAPESP) and the National Council for Scientific and Technological Development (CNPq - grant n. 406385/2018-1). DCP is a CNPq fellow researcher (grant n. 303792/2016-7). CeTICS is supported by FAPESP (grant n. 2013/07467-1). A FAPESP grant (n. 2013/07467-1) was used for acquisition of the Q-TOF mass spectrometer. JVATiTD publication is supported by the National Council for Scientific and Technological Development (CNPq) through Programa Editorial CNPq/CAPES (chamada n. 26/2017, processo n. 440954/2017-7). Therefore, all articles published by the journal are in part funded by this grant.

\section{Competing interests}

The authors declare that they have no competing interests.

\section{Authors' contributions}

All the authors contributed equally in this work. All authors read and approved the final manuscript.

\section{Ethics approval}

Not applicable.

\section{Consent for publication}

Not applicable.

\section{Supplementary material}

The following online material is available for this article:

Ádítionaí filie 1. de novo peptides identified from $D$. melanostictus A-SDF.

Ádítionaì filie $\overline{2}$. de novo peptides identified from $D$. melanostictus A-ADF.

\section{References}

1. Daly JW. The chemistry of poisons in amphibian skin. Proc Natl Acad Sci U S A. 1995;92(1):9-13.

2. Tracy CR, Christian KA, Tracy CR. Not just small, wet, and cold: effects of body size and skin resistance on thermoregulation and arboreality of frogs. Ecology. 2010;91(5):1477-84.

3. Larsen $\mathrm{EH}$, Ramlov $\mathrm{H}$. Role of cutaneous surface fluid in frog osmoregulation. Comp Biochem Physiol A Mol Integr Physiol. 2013;165(3):365-70.

4. Raaymakers C, Verbrugghe E, Hernot S, Hellebuyck T, Betti C, Peleman $C$, et al. Antimicrobial peptides in frog poisons constitute a molecular toxin delivery system against predators. Nat Commun. 2017;8(1):1495.

5. Toledo RC, Jared C. Cutaneous granular glands and amphibian venoms. Comp Biochem Physiol. 1995;111(1):1-29.

6. König E, Bininda-Emonds OR, Shaw C. The diversity and evolution of anuran skin peptides. Peptides. 2015;63:96-117.

7. Jared C, Antoniazzi MM, Jordão AE, Silva JR, Greven H, Rodrigues MT. Parotoid macroglands in toad (Rhinella jimi): their structure and functioning in passive defence. Toxicon. 2009;54(3):197-207.

8. Mailho-Fontana PL, Antoniazzi MM, Toledo LF, Verdade VK, Sciani JM, Barbaro KC, et al. Passive and active defense in toads: the parotoid macroglands in Rhinella marina and Rhaebo guttatus. J Exp Zool A Ecol Genet Physiol. 2014;321(2):65-77.
9. Vigerelli H, Sciani JM, Jared C, Antoniazzi MM, Caporale GM, Da Silva Ade $\mathrm{C}$, et al. Bufotenine is able to block rabies virus infection in $\mathrm{BHK}-21$ cells. J Venom Anim Toxins incl Trop Dis. 2014;20:45. doi: 10.1186/16789199-20-45.

10. Schmeda-Hirschmann G, Quispe C, Arana GV, Theoduloz C, Urra FA, Cárdenas C. Antiproliferative activity and chemical composition of the venom from the Amazonian toad Rhinella marina (Anura: Bufonidae). Toxicon. 2016;121:119-29.

11. Rodríguez C, Rollins-Smith L, Ibáñez R, Durant-Archibold A, Gutiérrez $M$. Toxins and pharmacologically active compounds from species of the family Bufonidae (Amphibia, Anura). J Ethnopharmacol. 2017;198:235-54.

12. Petroselli G, Raices M, Jungblut LD, Pozzi AG, Erra-Balsells R. MALDI-MS argininyl bufadienolide esters fingerprint from parotoid gland secretions of Rhinella arenarum: Age, gender, and seasonal variation. J Mass Spectrom. 2018;53(6):465-75.

13. Rash LD, Morales RA, Vink S, Alewood PF. De novo sequencing of peptides from the parotid secretion of the cane toad, Bufo marinus (Rhinella marina). Toxicon. 2011;57(2):208-16.

14. Huo $Y, X v R, M a H$, Zhou J, Xi X, Wu Q, et al. Identification of $<10$ $K D$ peptides in the water extraction of Venenum Bufonis from Bufo gargarizans using Nano LC-MS/MS and De novo sequencing. J Pharm Biomed Anal. 2018;157:156-64.

15. Sciani JM, Angeli CB, Antoniazzi MM, Jared C, Pimenta DC. Differences and similarities among parotoid macrogland secretions in South American toads: a preliminary biochemical delineation. ScientificWorldJournal. 2013;937407.

16. Zhao $Y$, Jin $Y$, Wei SS, Lee WH, Zhang Y. Purification and characterization of an irreversible serine protease inhibitor from skin secretions of Bufo andrewsi. Toxicon. 2005;46(6):635-40.

17. Zhao $Y$, Jin $Y$, Lee WH, Zhang Y. Purification of a lysozyme from skin secretions of Bufo andrewsi. Comp Biochem Physiol C Toxicol Pharmacol. 2006;142(1-2):46-52.

18. Sousa-Filho LM, Freitas CD, Lobo MD, Monteiro-Moreira AC, Silva RO, Santana LA, et al. Biochemical profile, biological activities, and toxic effects of proteins in the Rhinella schneideri parotoid gland secretion. J Exp Zool A Ecol Genet Physiol. 2016;325(8):511-23.

19. Kowalski K, Marciniak P, Rosiński G, Rychlik L. Toxic activity and protein identification from the parotoid gland secretion of the common toad Bufo bufo. Comp Biochem Physiol C Toxicol Pharmacol. 2018;205:43-52.

20. Weil AT, Davis W. Bufo alvarius: a potent hallucinogen of animal origin. J Ethnopharmacol. 1994;41(1-2):1-8.

21. Mariano DOC, Di Giacomo Messias M, Prezotto-Neto JP, Spencer PJ, Pimenta DC. Biochemical analyses of proteins from Duttaphrynus melanostictus (Bufo melanostictus) skin secretion: soluble protein retrieval from a viscous matrix by ion-exchange batch sample preparation. Protein J. 2018;37(4):380-9.

22. Ashburner M, Ball CA, Blake JA, Botstein D, Butler H, Cherry JM, et al. Gene ontology: tool for the unification of biology. The Gene Ontology Consortium. Nat Genet. 2000;25(1):25-9.

23. Tempone AG, Pimenta DC, Lebrun I, Sartorelli P, Taniwaki NN, de Andrade HFJr, et al. Antileishmanial and antitrypanosomal activity of bufadienolides isolated from the toad Rhinella jimi parotoid macrogland secretion. Toxicon. 2008;52(1):13-21.

24. Anjolette FA, Leite FP, Bordon KC, Azzolini AEC, Pereira JC, PereiraCrott LS, et al. Biological characterization of compounds from Rhinella schneideri poison that act on the complement system. J Venom Anim Toxins incl Trop Dis. 2015;13:21-5. doi: 10.1186/s40409-015-0024-9.

25. Liu SB, He YY, Zhang Y, Lee WH, Qian JQ, Lai R, et al. A novel non-lens betagamma-crystallin and trefoil factor complex from amphibian skin and its functional implications. PLoS One. 2008;3(3):e1770.

26. Zhang Y, Wang M, Wei S. Isolation and characterization of a trypsin inhibitor from the skin secretions of Kaloula pulchra hainana. Toxicon. 2010;56(4):502-7.

27. Demesa-Balderrama G, Meneses EP, Hernández-Orihuela L, PandoRobles $\mathrm{V}$, Rodriguez MC, Barrientos-Salcedo C, et al. A Comprehensive proteomic study of the skin secretions of the frog Lithobates spectabilis. Protein Pept Lett. 2016;23(7):597-611. 
28. Cavalcante ID, Antoniazzi MM, Jared C, Pires ORJr, Sciani JM, Pimenta DC. Venomics analyses of the skin secretion of Dermatonotus muelleri: Preliminary proteomic and metabolomic profiling. Toxicon. 2017;130:127-35.

29. Kawasaki $H$, Isaacson $T$, Iwamuro S, Conlon JM. A protein with antimicrobial activity in the skin of Schlegel's green tree frog Rhacophorus schlegelii (Rhacophoridae) identified as histone H2B. Biochem Biophys Res Commun. 2003;312(4):1082-6.

30. Penning TM. The aldo-keto reductases (AKRs): Overview. Chem Biol Interact. 2015;234: 236-46.

31. Berchtold MW, Villalobo A. The many faces of calmodulin in cell proliferation, programmed cell death, autophagy, and cancer. Biochim Biophys Acta. 2014;1843(2):398-435.

32. Camby I, Le Mercier M, Lefranc F, Kiss R. Galectin-1: a small protein with major functions. Glycobiology. 2006;16(11):137R-57R.

33. Parseghian $\mathrm{MH}$, Luhrs KA. Beyond the walls of the nucleus: the role of histones in cellular signaling and innate immunity. Biochem Cell Biol. 2006;84(4):589-604.

34. Hori T, Yokomizo T, Ago H, Sugahara M, Ueno G, Yamamoto M, et al. Structural basis of leukotriene B4 12-hydroxydehydrogenase/15Oxo-prostaglandin 13-reductase catalytic mechanism and a possible Src homology 3 domain binding loop. J Biol Chem. 2004;279(21):22615-23.

35. Swinnen JV, Alen P, Heyns W, Verhoeven G. Identification of diazepambinding Inhibitor/Acyl-CoA-binding protein as a sterol regulatory elementbinding protein-responsive gene. J Biol Chem. 1998;273(32):19938-44.
36. Neess D, Bek S, Engelsby H, Gallego Sf, Færgeman NJ. Long-chain acyl-CoA esters in metabolism and signaling: Role of acyl-CoA binding proteins. Prog Lipid Res. 2015;59:1-25.

37. Knudsen J, Mandrup S, Rasmussen JT, Andreasen PH, Poulsen F, Kristiansen $\mathrm{K}$. The function of acyl-CoA-binding protein (ACBP)/diazepam binding inhibitor (DBI). Mol Cell Biochem. 1993;123(1-2):129-38.

38. Bloksgaard M, Neess D, Færgeman NJ, Mandrup S. Acyl-CoA binding protein and epidermal barrier function. Biochim Biophys Acta. 2014;1841(3):369-76.

39. Regis-Alves E, Jared SJS, Maurício B, Mailho-Fontana PI, Antoniazzi MM, Fleury-Curado MC, et al. Structural cutaneous adaptations for defense in toad (Rhinella icterica) parotoid macroglands. Toxicon. 2017;137:128-34.

40. Chi H, Chen H, He K, Wu L, Yang B, Sun RX, et al. pNovo+: de novo peptide sequencing using complementary HCD and ETD tandem mass spectra. J Proteome Res. 2013;12(2):615-25.

41. Shibao PYT, Cologna CT, Morandi-Filho R, Wiesel GA, Fujimura PT, Ueira-Vieira C, et al. Deep sequencing analysis of toad Rhinella schneideri skin glands and partial biochemical characterization of its cutaneous secretion. J Venom Anim Toxins incl Trop Dis. 2018;24:36. doi.org/10.1186/ s40409-018-0173-8. 